\title{
N91-10895
}

\section{Yisualization of Fluid Dynamics at NASA Ames}

\author{
Val Watson \\ NASA Ames Research Center
}

The hardware and software currently used for visualization of fluid dynamics at NASA Ames is described. The software includes programs to create scenes (for example particle traces representing the flow over an aircraft), programs to interactively view the scenes, and programs to control the creation of video tapes and $16 \mathrm{~mm}$ movies. The hardware includes high performance graphics workstations, a high speed network, digital video equipment, and film recorders.

With the current workstations, a scientist can interactively view flow over simplified objects, such as the flow over a circular cylinder. For complex objects, such as an aircraft, the workstation creates each picture too slowly to gain a sense of the dynamics of the flow. Therefore, each picture is stored frame by frame on a video tape or $16 \mathrm{~mm}$ film and then the video or movie is played back at normal speed to illustrate the flow dynamics.

The upgrade in workstations planned for this year is expected to permit moderately complex pictures (pictures that can be represented by 10,000 polygons or less) to be created at a rate of 10 frames per second --- fast enough to gain a sense of the flow dynamics. Therefore, these workstations should permit interactive viewing of the flow over complete aircraft rather than just simple objects. Upgrades planned this year for software should provide a more effective interface for controlling the interactive viewing.

A comparison of the upgrades planned this year with an ideal simulation and visualization environment shows that there is still potential for major improvements in both software and hardware. The greatest potential for improving the environment is the development of software to extract and illustrate the essence of very complex phenomena.

Results presented by other scientists during this conference clearly demonstrate the effectiveness of the current visualization tools for assisting in the understanding of complex simulations, but it is also clear that we are a long way from utilizing visualization tools to their full extent. 


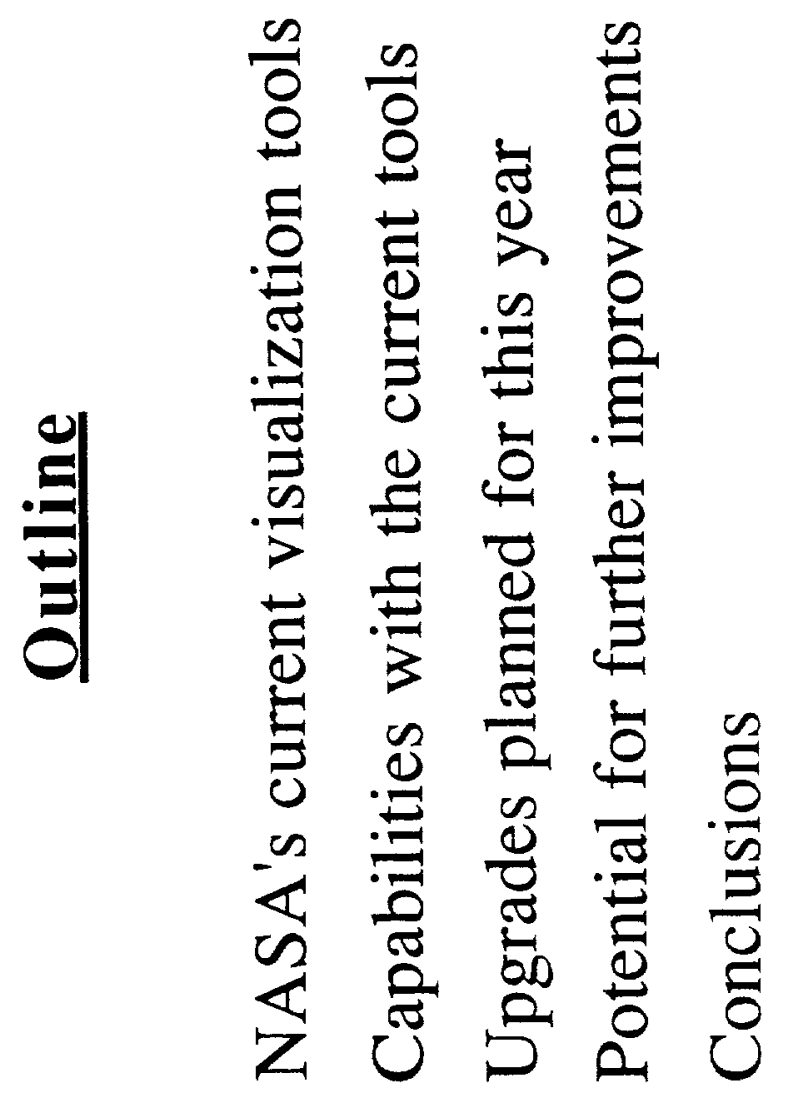




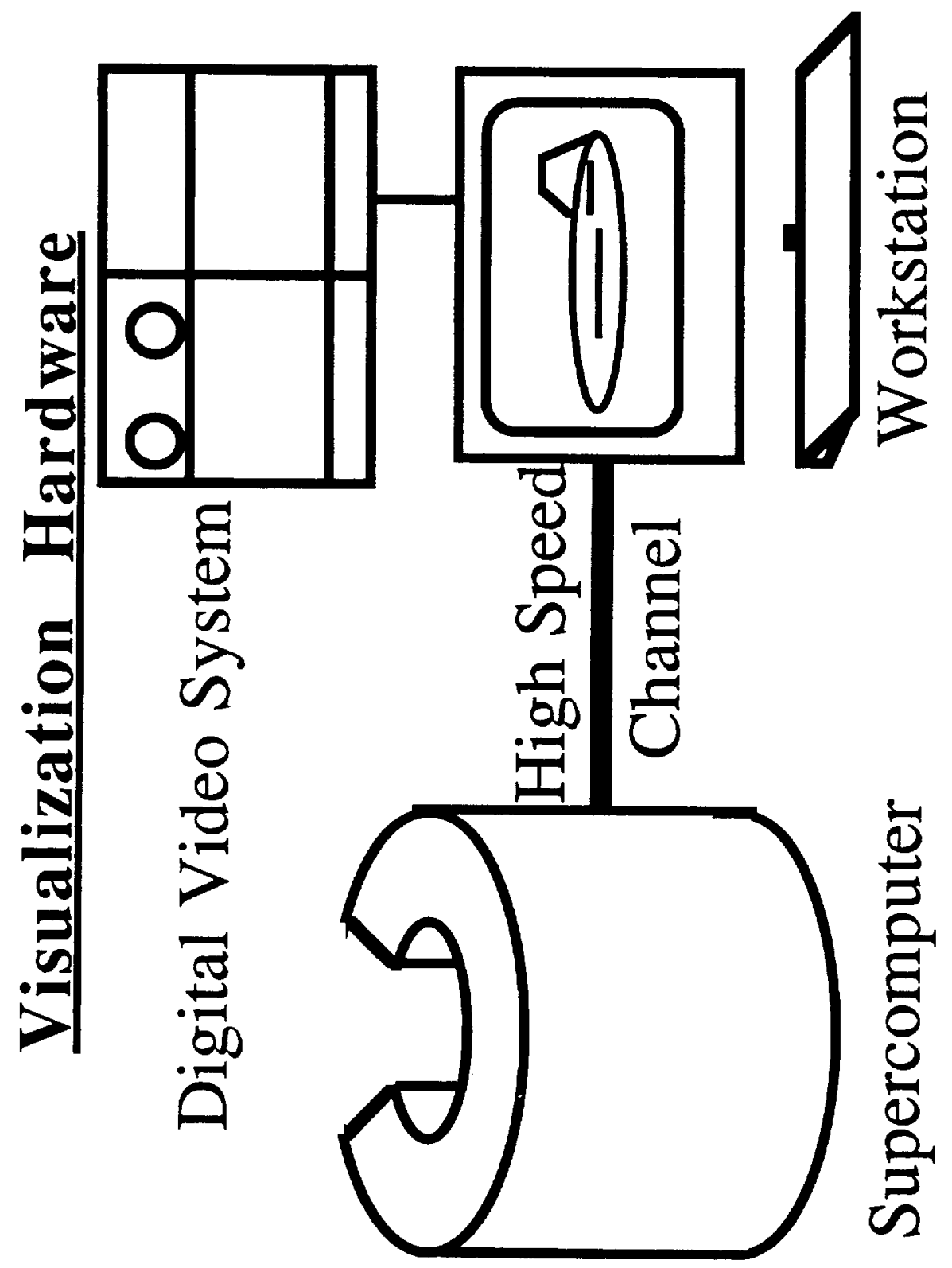




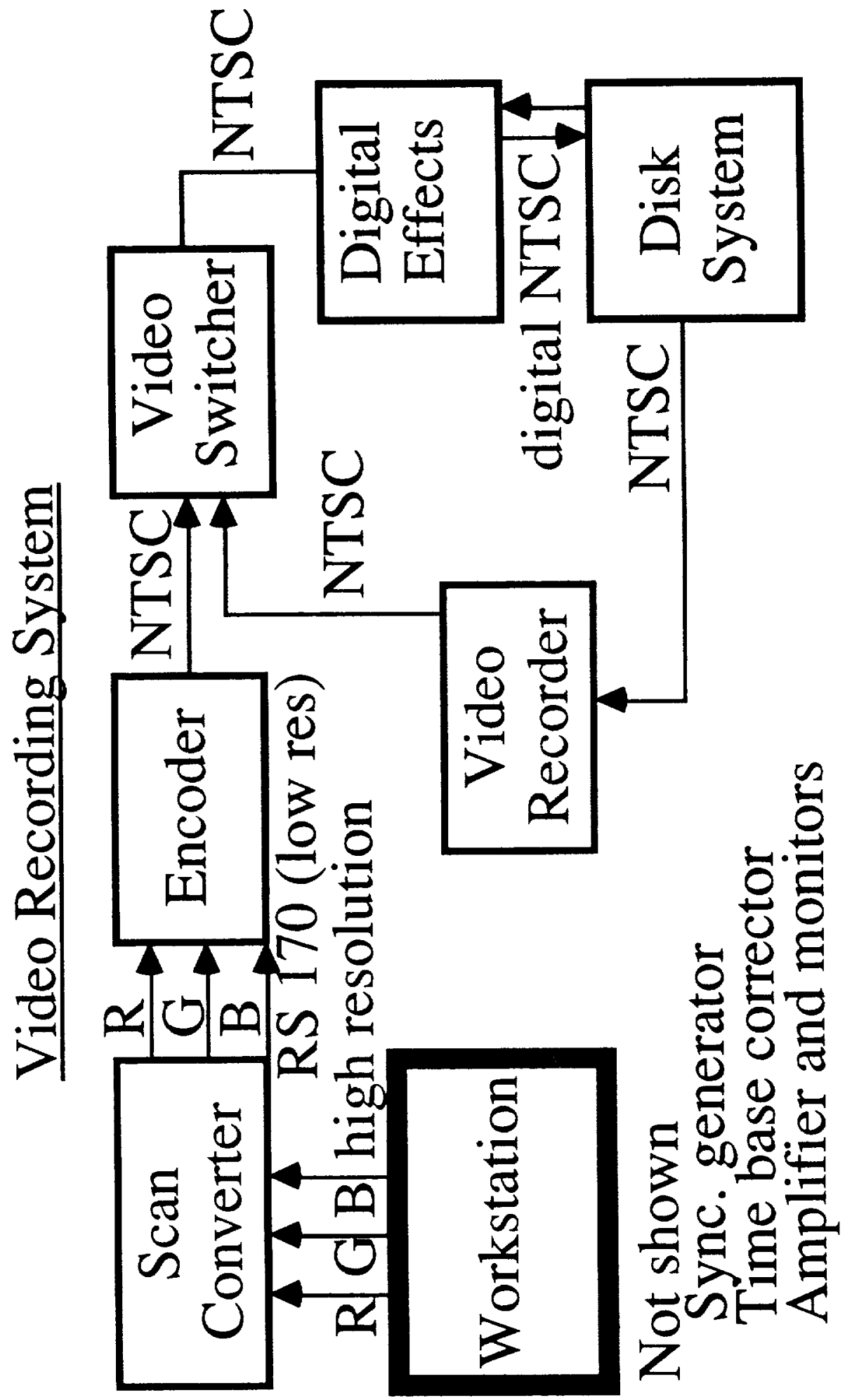




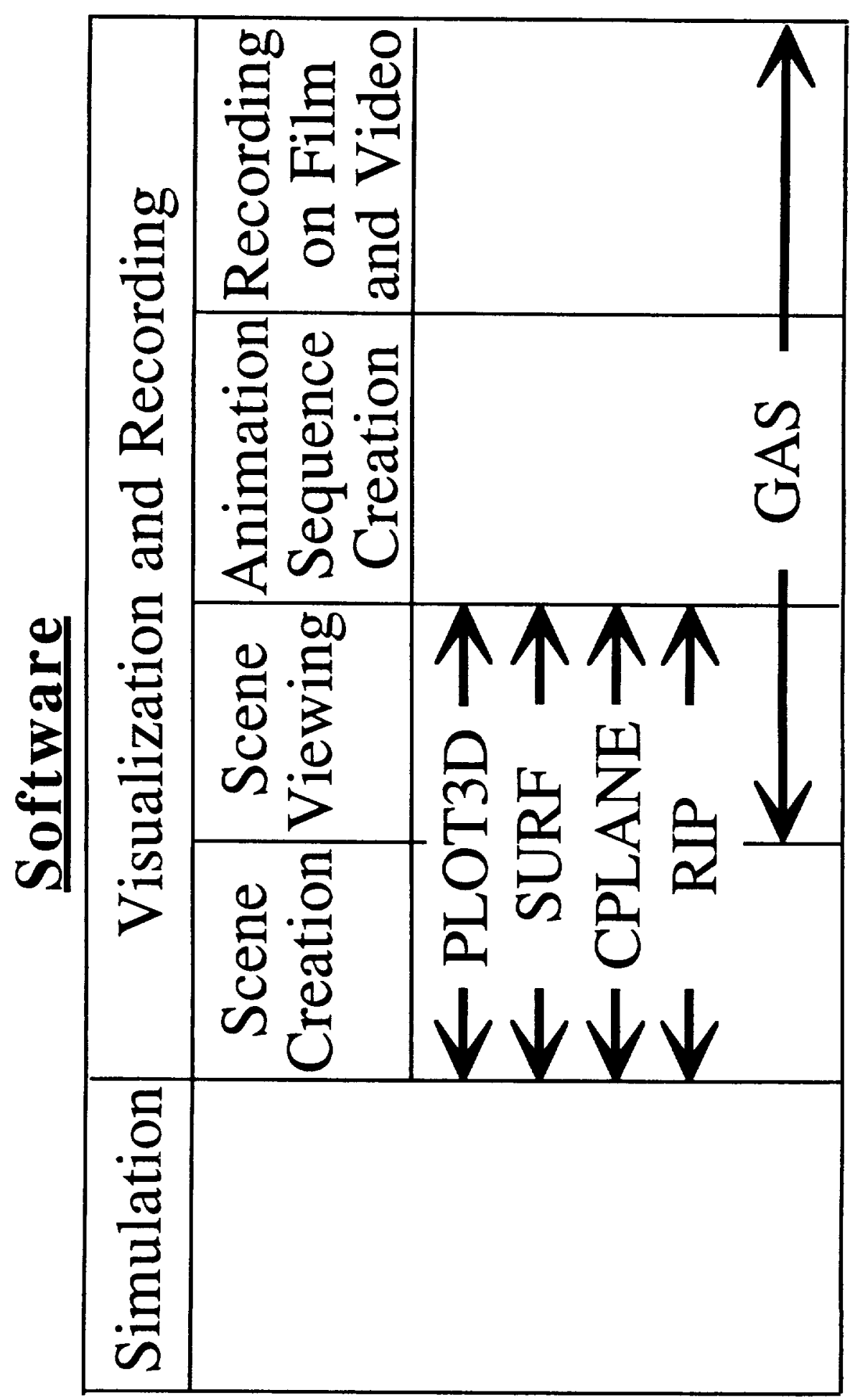




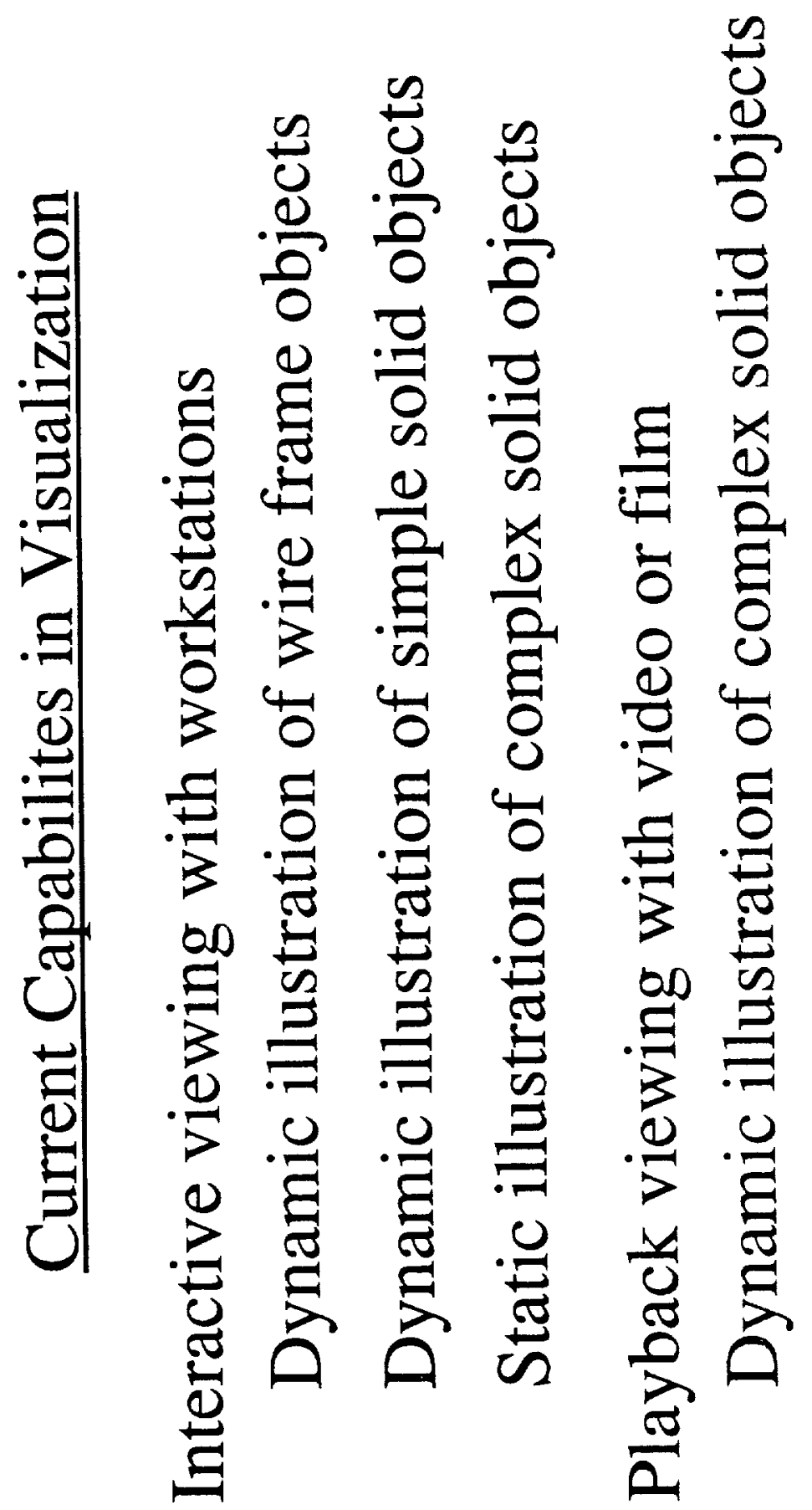




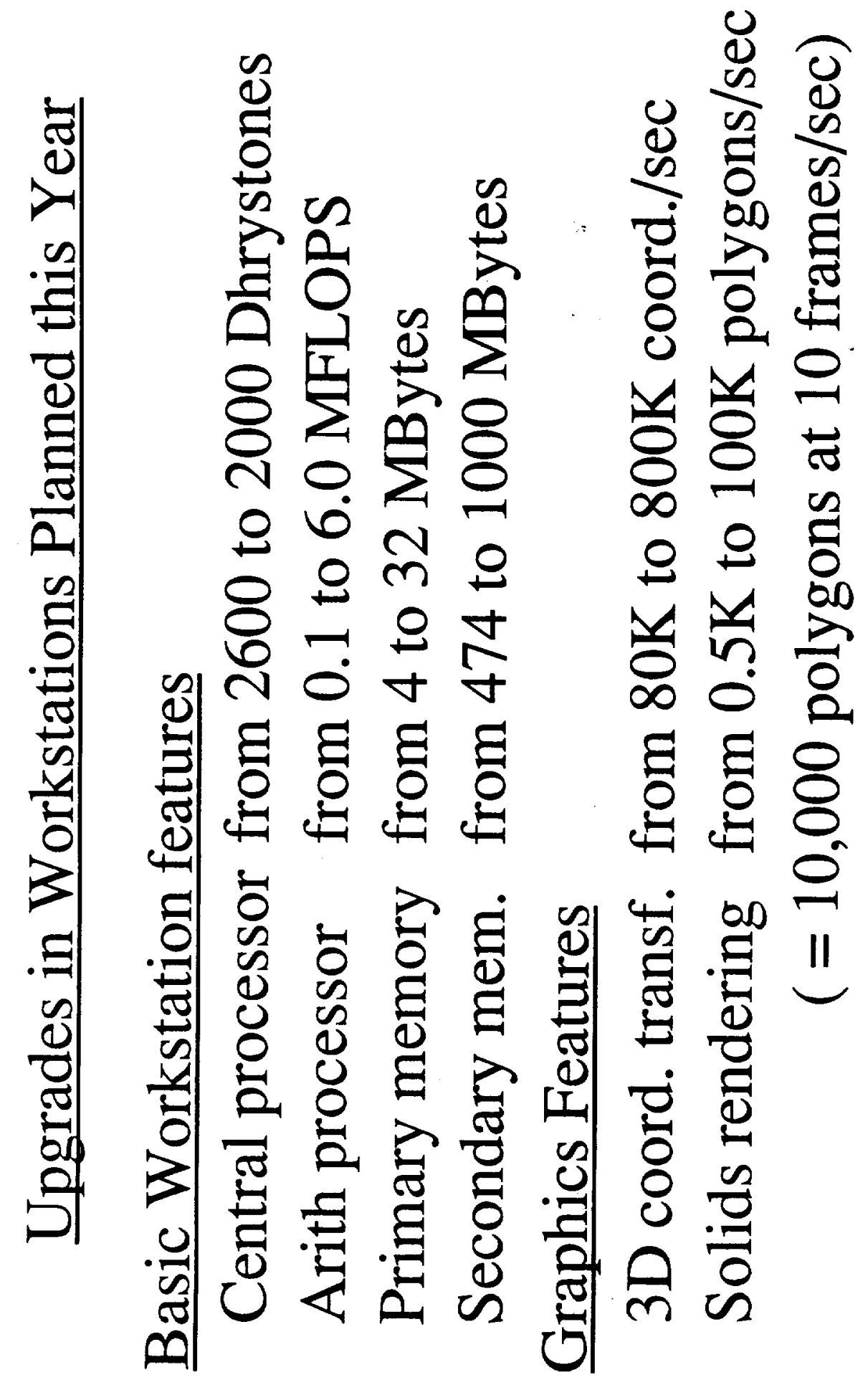




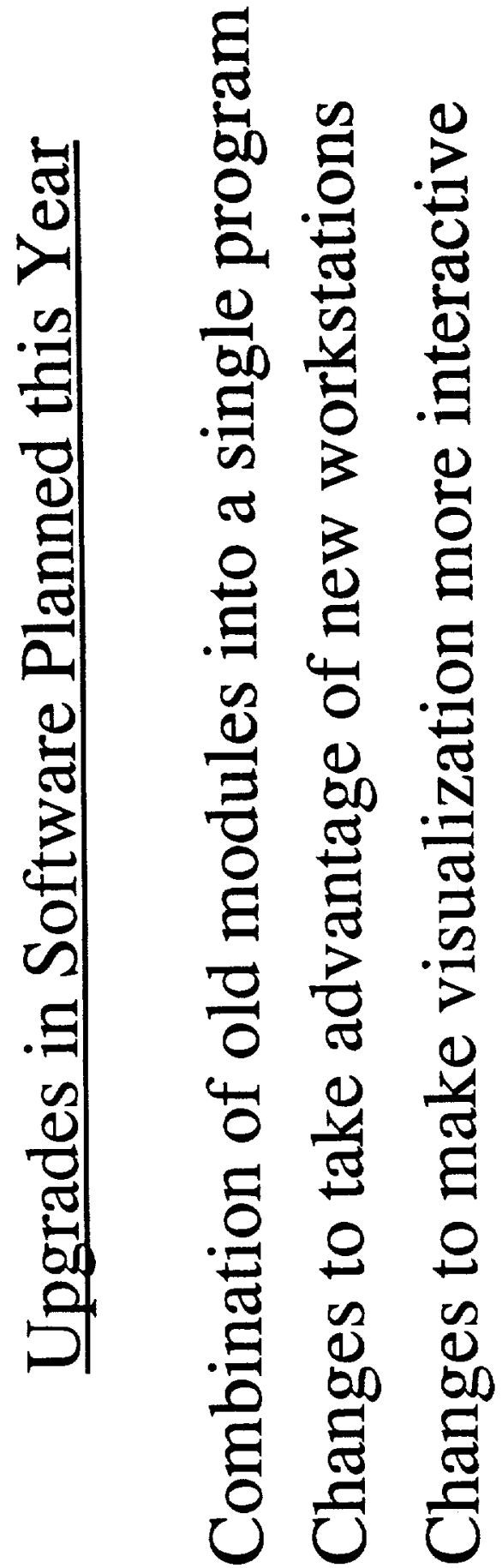



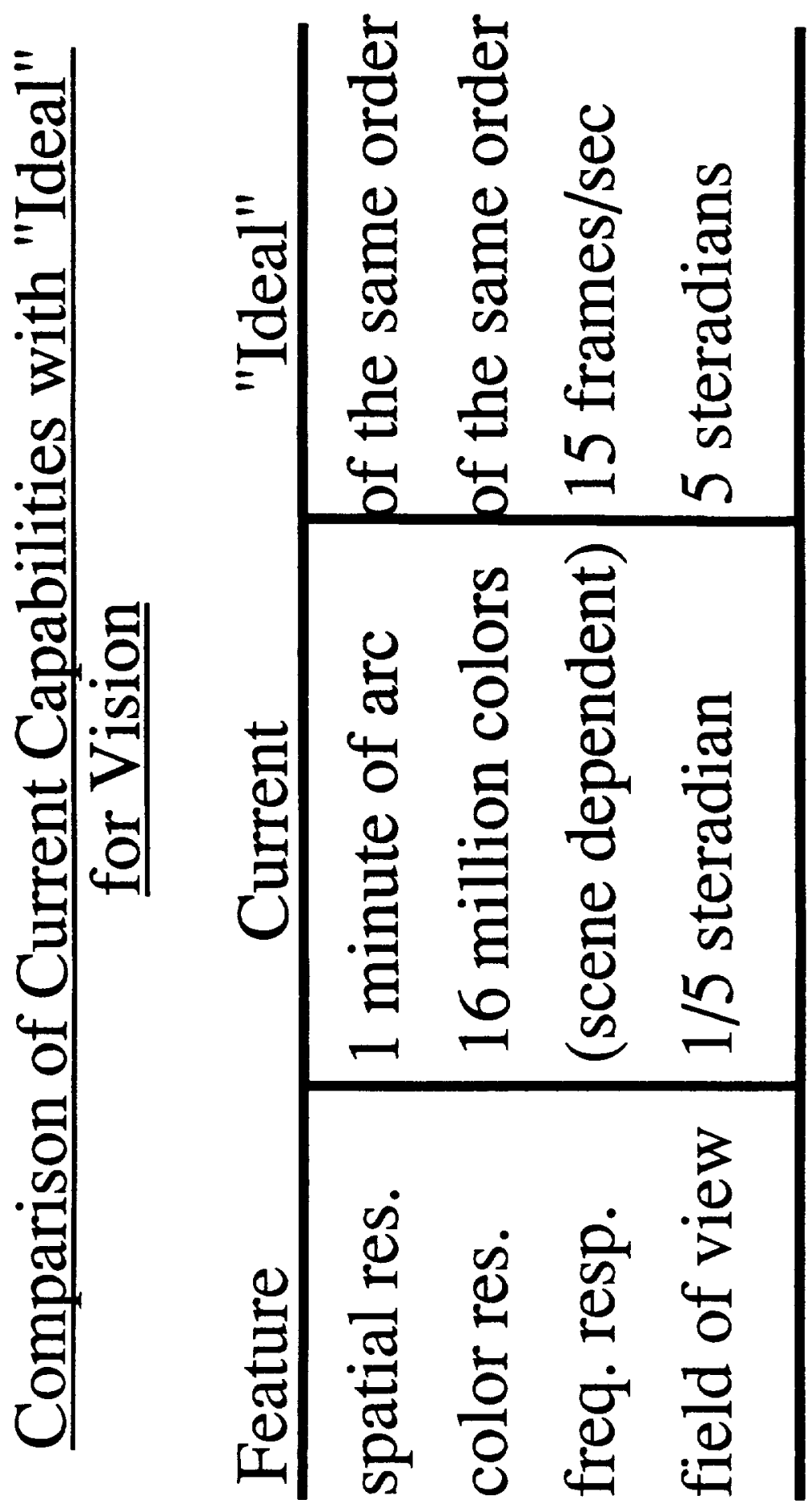


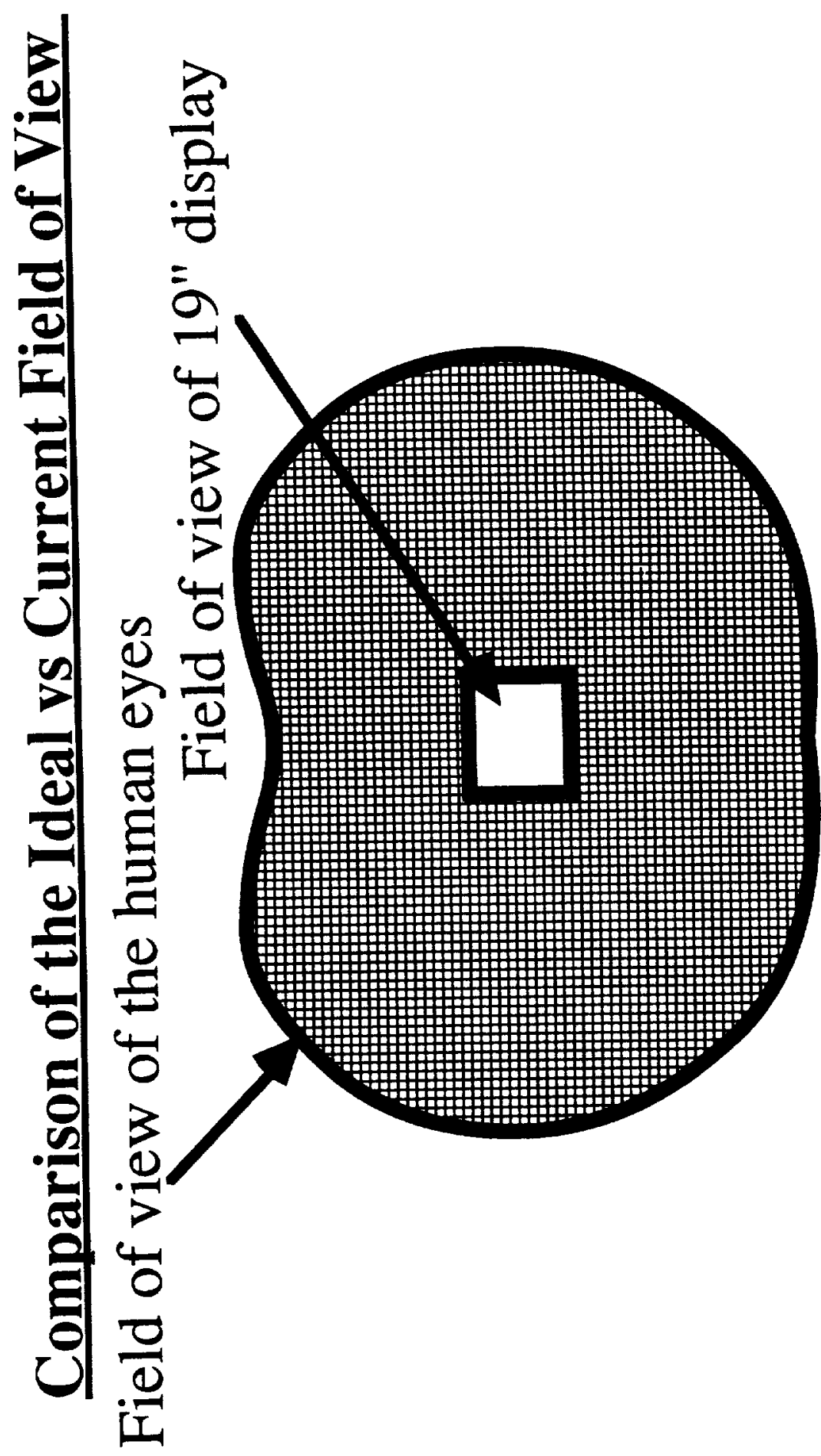



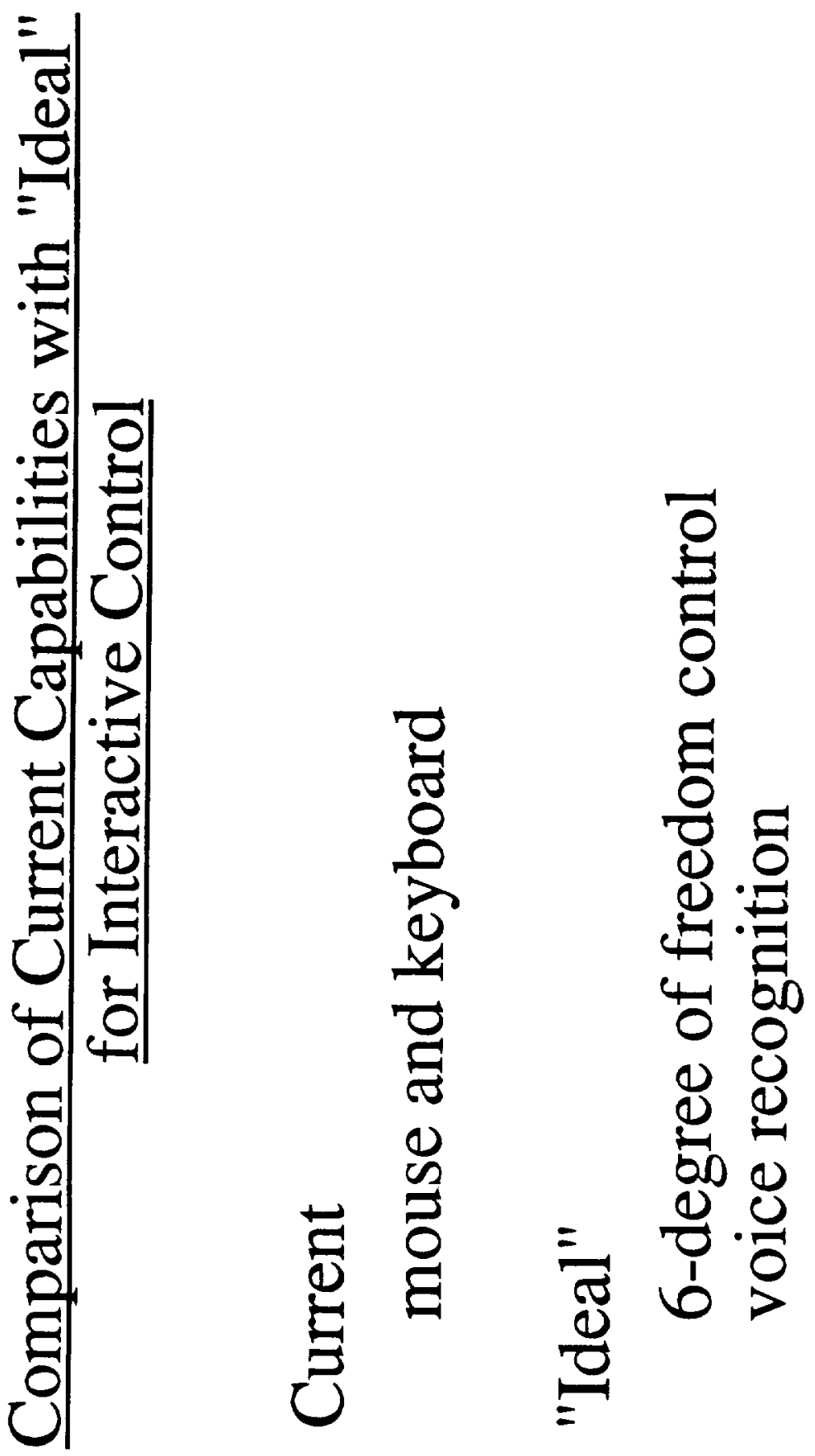


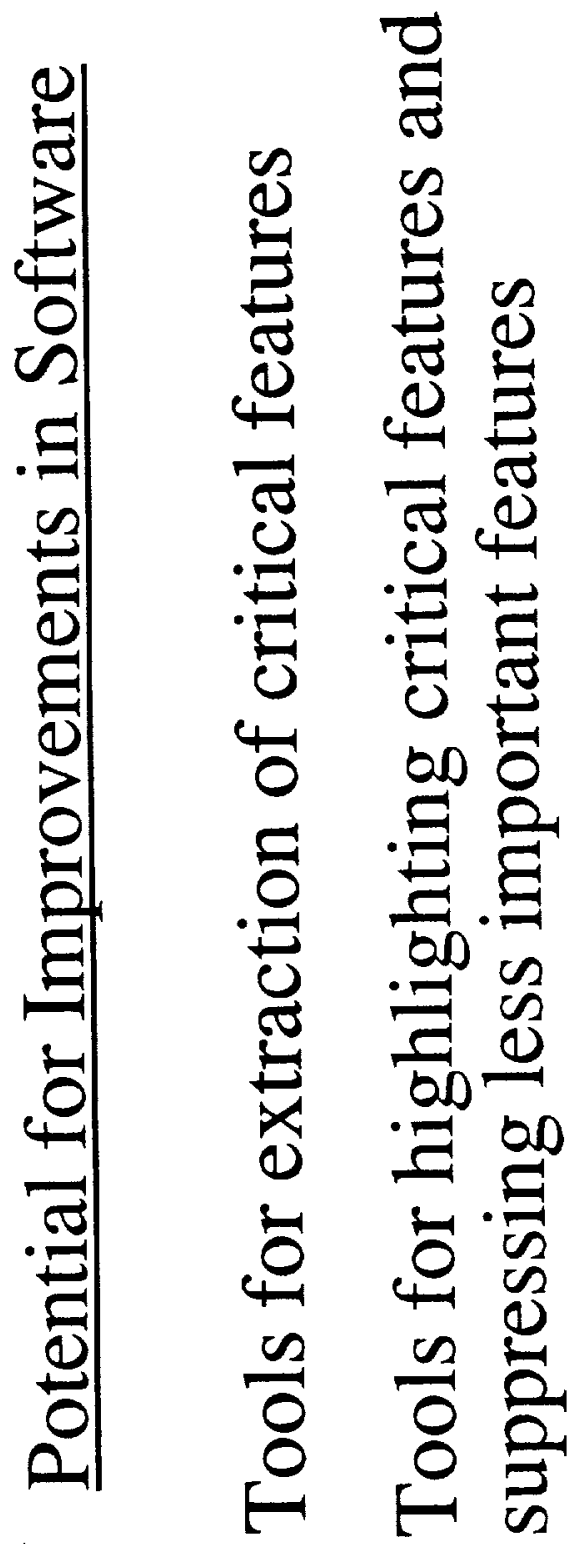




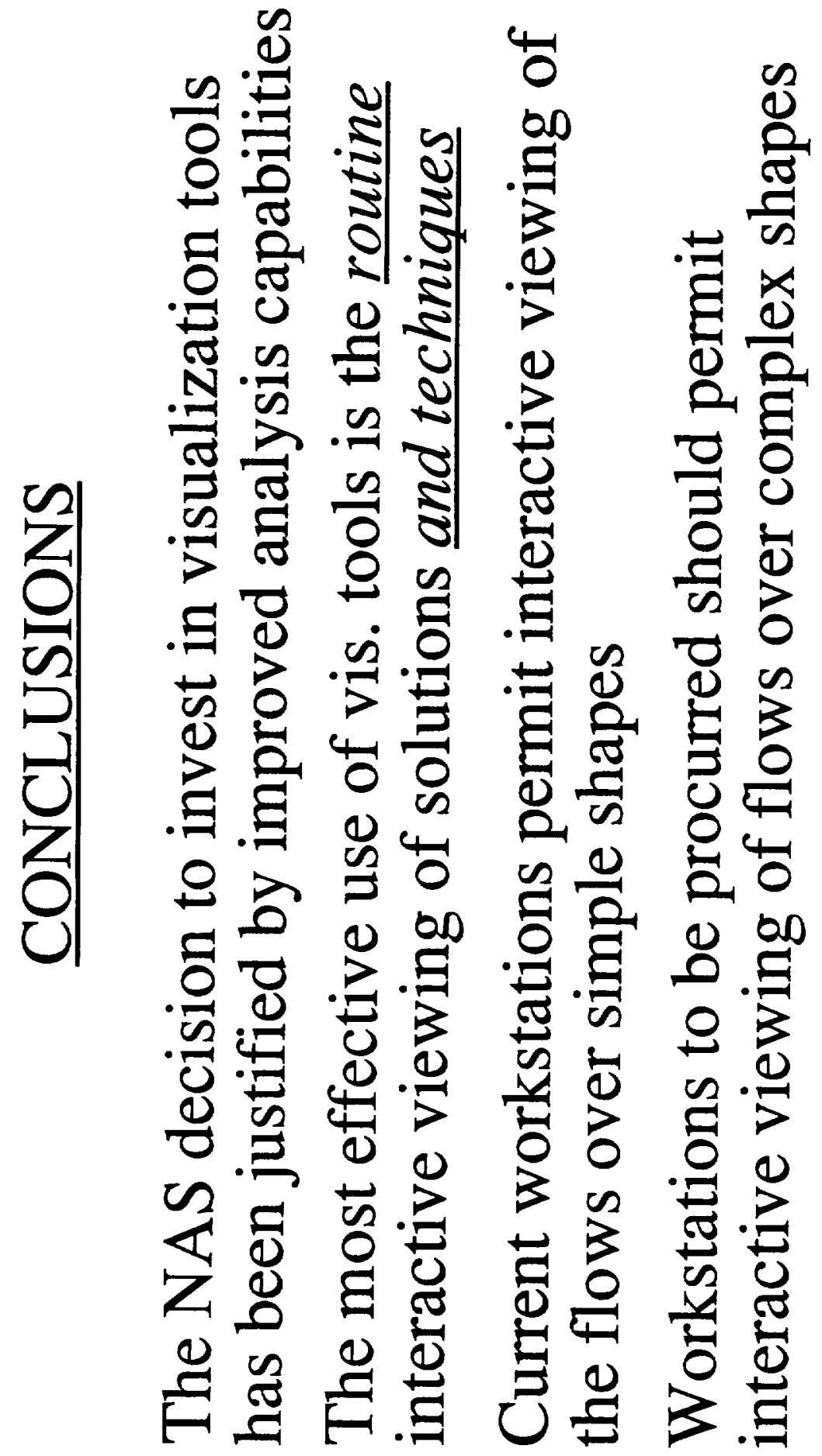




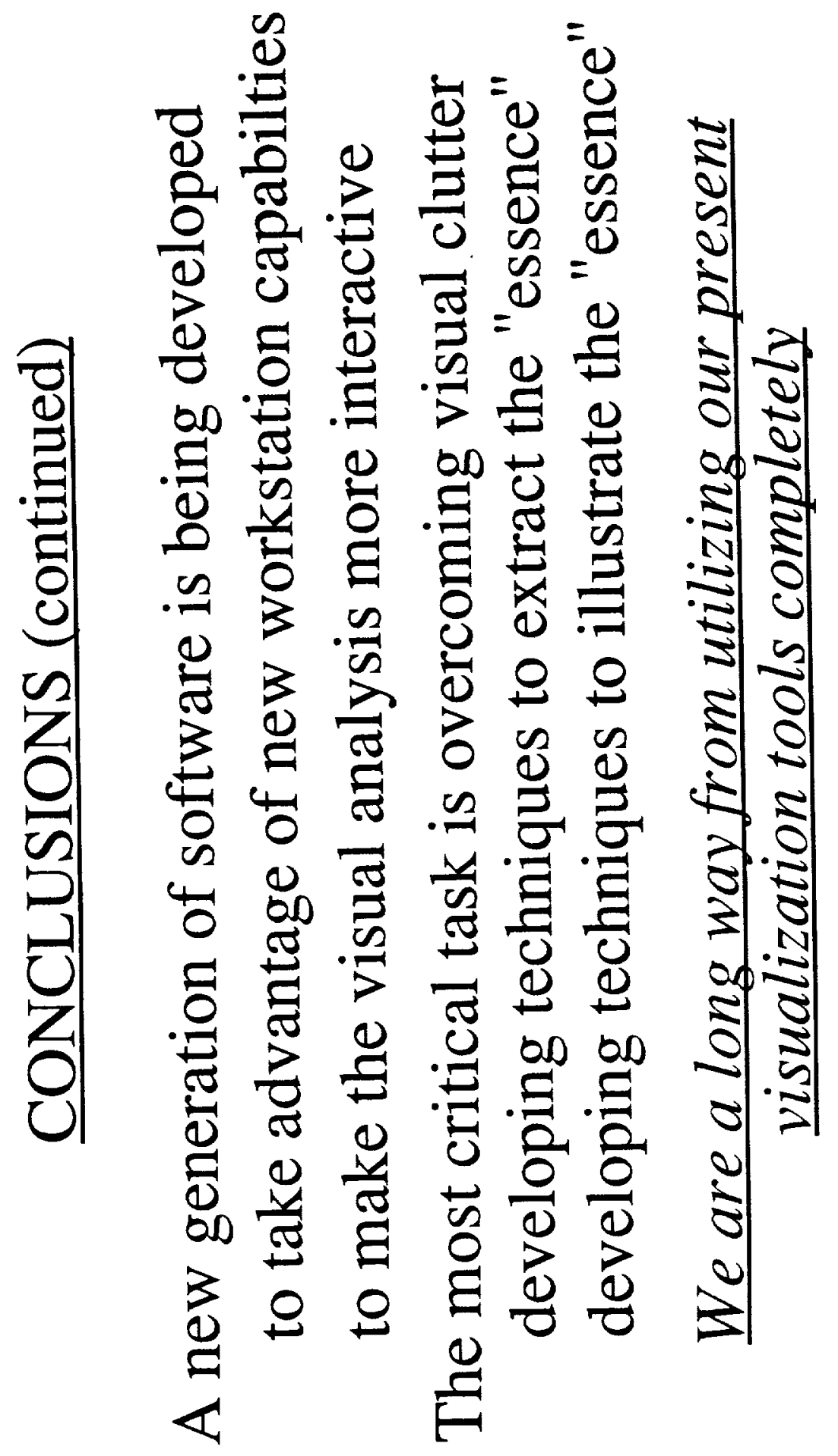




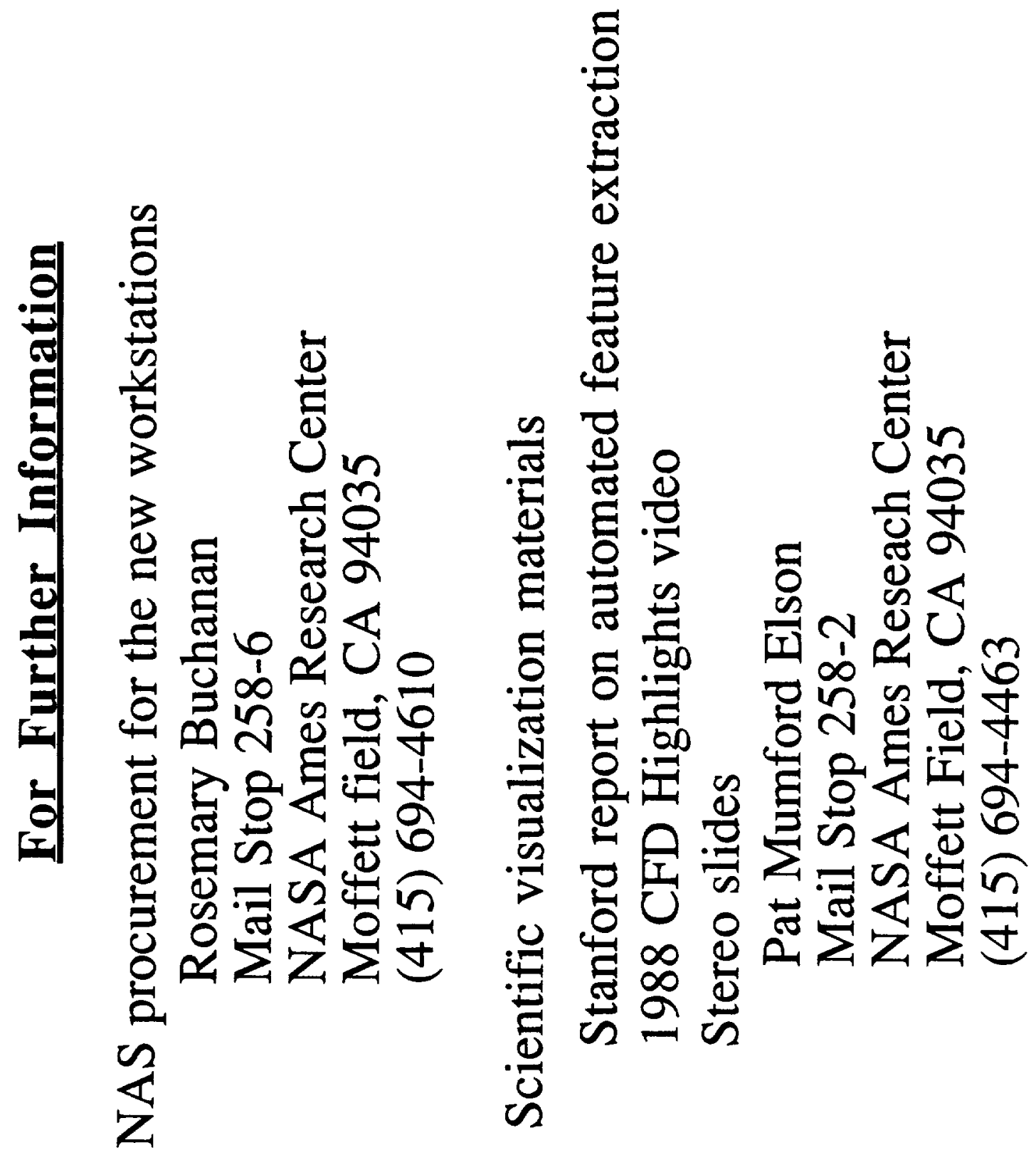


